Short Communication

\title{
Facile Synthesis of Silicon Nanoparticles Embedded in 3D N- doped Graphene as Anode Materials for High-Performance Lithium Ion Batteries
}

\author{
Junli Li ${ }^{1}$, Ruihong $\mathrm{Li}^{1, *}$, Chaoke Bulin ${ }^{1}$, Ruiguang Xing ${ }^{1}$, Bangwen Zhang ${ }^{1,2, *}$ \\ ${ }^{1}$ School of Material and Metallurgy, Inner Mongolia University of Science \& Technology, Baotou \\ 014010, China \\ ${ }^{2}$ Instrumental Analysis Center, Inner Mongolia University of Science \& Technology, Baotou 014010, \\ China \\ *E-mail: $\underline{\text { liruihong1019@163.com, bangwenz@126.com }}$
}

doi: $10.20964 / 2017.05 .16$

Received: 26 January 2017 / Accepted: 28 February 2017 / Published: 12 April 2017

The Si nanoparticle embedded in three dimensional nitrogen-doped graphene ( $\mathrm{Si}-\mathrm{NG}$ ) composite was synthesized by a facile one-step hydrothermal method using urea as nitrogen source and vitamin $\mathrm{C}$ as reducing agent of graphene oxide. The composites were investigated with regard to the composition and structure by various instrumental methods and the electrochemical performances as the freestanding anode of LIBs. The results show that the Si-NG composite anode affords high storage energy and rate capability. A high discharge capacity of $1373 \mathrm{mAhg}^{-1}$ over 100 cycles is obtained at $400 \mathrm{~mA} \mathrm{~g}^{-1}$, with coulombic efficiency of $98.3 \%$. The excellent electrochemical performance is associated with high electrical conductivity of N-doped 3D graphene, short transportation path for both lithium-ions and electrons due to nanocrystallization of $\mathrm{Si}$, and elastomeric space to accommodate volume changes during alloying/dealloying.

Keywords: silicon nanoparticle; Nitrogen-doped graphene; freestanding; anode; lithium-ion batteries

\section{FULL TEXT}

(C) 2017 The Authors. Published by ESG (www.electrochemsci.org). This article is an open access article distributed under the terms and conditions of the Creative Commons Attribution license (http://creativecommons.org/licenses/by/4.0/). 